\title{
Type specimens online: What is available, what is not, and how to proceed; Reflections based on an analysis of the images of type specimens of southern African Polygala (Polygalaceae) accessible on the worldwide web
}

\author{
Gideon F. Smith ${ }^{1,2,3}$ \& Estrela Figueiredo ${ }^{1,4}$ \\ 1 Centre for Functional Ecology, Departamento de Ciências da Vida, Universidade de Coimbra, 3001-455 Coimbra, Portugal \\ 2 Office of the Chief Director: Biosystematics Research \& Biodiversity Collections, South African National Biodiversity Institute, \\ Private Bag X101, Pretoria, 0001 South Africa \\ 3 H.G.W.J. Schweickerdt Herbarium, Department of Plant Science, University of Pretoria, Pretoria, 0002 South Africa \\ 4 Department of Botany, P.O. Box 77000, Nelson Mandela Metropolitan University, Port Elizabeth, 6031 South Africa \\ Author for correspondence: Estrela Figueiredo, estrelafigueiredo@hotmail.com
}

\begin{abstract}
The results of a gap analysis of the availability of internet-hosted images of the types of names of Polygala L. (Polygalaceae) in southern Africa accessible at JSTOR Global Plants (JGP) and on other sites in the worldwide web, are presented. The type information for names associated with this genus was recorded and analyzed with a view to suggest ways in which JGP and other internet resources that host specimen images might further expand and enrich their e-holdings, and to identify which non-partner institutions should be approached to collaborate in the Global Plants Initiative (GPI), the most successful specimen imaging thrust ever. Our analysis shows that images of 52\% of the types of southern African Polygala names (208 names assessed) are accessible at JGP. Of these images, $74 \%$ have incorrect metadata or no information on what sort of type it depicts. For $25 \%$ of the accepted taxa of Polygala, no images of the types of their names are available online. This gap can mostly be filled by GPI partners who hold the majority of the types not yet imaged, most of which are likely not in type folders or do not carry annotations indicating their type status. JGP would significantly benefit from directly contracting taxonomic services to improve the quality of its data on types, thus enabling information to be fed back to partner institutions.
\end{abstract}

Keywords electronic images of plant specimens; gap analysis; Global Plants Initiative; herbarium specimens; JSTOR Global Plants; taxonomy

Received: 14 Mar. 2013; revision received: 6 June 2013; accepted: 14 June 2013. DOI: http://dx.doi.org/10.12705/624.5

\section{INTRODUCTION}

"... a type-specimen, one of those bottled Platonic essences that define everything like them.' China Miéville, Kraken, 2010: 9

Because type specimens of plant names, unlike the type specimen of Miéville's giant squid quoted above, are usually not bottled, but rather preserved virtually two-dimensionally they can be digitally imaged using existing and widely available technology with great ease and at comparatively affordable expense on a large scale. In the early 2000s these factors, among others, prompted the establishment of the first comprehensive international enterprise, the African Plants Initiative (API), to venture into this territory (Smith, 2004; Walters \& al., 2010; Smith \& al., 2011). Migrating from the API, through the Latin American Plants Initiative, today's Global Plants Initiative (GPI), with 274 participating herbaria from 71 countries (Deirdre Ryan, pers. comm.), is one of the most profoundly useful and influential projects launched in plant systematics over the past two decades. One of the primary objectives of this project is to create and disseminate electronic images of the types of plant names at an unprecedented global scale. The benefits of having this e-resource available to botanical researchers are widely understood and recognized (Smith \& Figueiredo, 2010; Marhold \& al., 2013).

During the past ten years significant monetary investment, mostly by the Andrew Mellon Foundation, has enabled the imaging and dissemination of hundreds of thousands of type and other specimens, as well as related botanical artifacts such as collecting books and registers, and photographic images of living plants, which are accessible online via JSTOR Global Plants (JGP). At a smaller scale other individual herbaria have embarked on similar imaging projects. With funding for the GPI from the Mellon Foundation coming to an end in 2013/2014, a GPI Steering Committee (GPI SC) that aims to provide leadership to the GPI community of partners, ensuring that the partnership continues to flourish and develop into the future, was elected in October 2012 (Global Plants Initiative Steering Committee, 2013). The GPI SC intermittently met in Panama City, Panama, in the week of 7 to 11 January 2013, during the GPI meeting, to further discuss how this aim will be achieved.

One of the topics discussed during these meetings was the need to conduct a gap analysis to determine which non-partner 
herbaria should be approached to join the GPI and contribute their content to this thrust. The goal is to determine which herbaria have holdings that would add significant new content to complement that already available through the current GPI partners. Furthermore the analysis would help determine which plant groups are under-represented at JGP. At the Panama City meeting Helga Ochoterena (Instituto Biología, UNAM, Mexico) presented and later refined, with Eimear Niclughadha (Royal Botanic Gardens, Kew), a possible broad-based way in which such an analysis could be conducted (H. Ochoterena, pers. comm.). In piloting gap analyses of specific groups of plants that occur in a defined geographical area, our approach presented here is intended to complement that proposed by Ochoterena through being based on a recent synopsis and current revisionary work.

This paper reports on a gap analysis conducted on the e-availability of types of names of southern African taxa of Polygala L. (Polygalaceae). Globally, the genus Polygala consists of about 330 species (Paiva, 1998). It has a nearcosmopolitan geographical distribution range in mild- to temperate-climate parts of the world. Most species are forbs, shrubs or trees. Polygala taxa have beautiful pseudo-legume shaped flowers that have attracted the attention of both professional and amateur botanists. With ca. 80 species $(25 \%$ of the genus) recorded for southern Africa, Polygala has diversified extensively on the subcontinent. Including infraspecific categories, 87 taxa are known from the region (Figueiredo $\&$ al., subm.).

This group was chosen because a recent synopsis is available for it (Paiva, 1998) and it is currently being revised in depth for the Flora of Southern African (FSA) region (South Africa, Botswana, Namibia, Lesotho, Swaziland). The FSA region has been subject to over three-and-a-half centuries of colonial involvement, and most historical specimens prepared of southern African plants were shipped to and are housed in foreign institutions (Figueiredo \& Smith, 2010), which is reflected in the scarcity of type material in the subcontinent (see tables below) which emphasizes the need for improved access to electronic images.

Based on the outcomes of this analysis we propose ways in which JGP can further expand and enrich its e-holdings of specimen images as well as the associated data, and which institutions that are currently not partners could be approached to collaborate in the GPI.

\section{MATERIALS AND METHODS}

The revision of Polygala in the FSA region has assessed 208 names and their types (Figueiredo \& al., subm.). Information on type specimens was collated and checked in the current revision, compiled from the literature, especially Paiva (1998), and complemented with searches in JSTOR Global Plants (2013), the Zürich Herbaria Database (2013), Geneva Herbaria Catalogue (2013), Kew Herbarium Catalogue (2013), The Linnaean Collections (2013) and Uppsala Herbarium (UPS) Database (2013).

\section{RESULTS AND DISCUSSION}

Types of southern African Polygala. - A total of 477 type specimens (including duplicates, e.g., isotypes, isosyntypes, and isolectotypes, but not paratypes nor non-specimen types) were recorded (Table 1) for southern African Polygala. This figure does not include numerous further duplicates that exist in herbaria but that are not cited in the literature, nor databased and therefore not detectable. For 8 names the type could not be located or is unknown, and for 13 names the holotype was determined to be destroyed. One hundred and twenty-six names have a holotype or lectotype, and with the designation of 19 additional lectotypes (Figueiredo \& al., subm.), this number will increase to 145 . Lectotypification or neotypification will still be required for the remaining names.

The great majority of the herbaria holding the types of Polygala names recorded for the FSA region are located in Europe (Table 2). Two South African herbaria (BOL, PRE) are the only regional institutions with more than 10 types each.

The herbaria with the largest number of types are $\mathrm{K}$ and $\mathrm{BM}$, which reflects the fact that most taxonomic activity on the genus for the region took place in the 19th century when these institutions (as well as several continental European herbaria) were centres for research on the flora of Africa (Tables 2, 3). Significantly, the sharp drop in the number of new names published from 1951 to the present is likely an indication of a stable and dependable taxonomy being available for southern African Polygala. New species are nevertheless still being recorded, with at least two awaiting description.

Surprisingly none of the main authors of Polygala names for the region (Table 4) were based at K and BM. The most prolific author of southern African Polygala names, R.H. Chodat, with 52 published, was based at G. However, many types of his names have not been located in that herbarium. An examination of the protologues of Chodat's names shows that, while he

Table 1. Polygala names and types in the FSA region.

\begin{tabular}{|c|c|}
\hline & Number \\
\hline Names & 208 \\
\hline Basionyms & 185 \\
\hline Type specimens ${ }^{\mathrm{a}}$ & 477 \\
\hline Holotypes & 85 \\
\hline Extant holotypes & 72 \\
\hline Holotypes destroyed & 13 \\
\hline Lectotypes & 54 \\
\hline Lectotypes to be designated ${ }^{\mathrm{b}}$ & 19 \\
\hline
\end{tabular}

Number of names for which types are syntypes (or syntype collection, where more than one duplicate exists but no holotype has been designated)

Names for which the type specimen is unknown or not designated

${ }^{a}$ The types of five names are not specimens, and are excluded from this figure.

${ }^{\mathrm{b}}$ Figueiredo \& al., subm. 
Table 2. Herbaria holding types of southern African Polygala names.

\begin{tabular}{|c|c|c|c|c|}
\hline Herbarium & $\begin{array}{l}\text { Types of } \\
\text { Polygala } \\
\text { names } \\
\text { from } \\
\text { southern } \\
\text { Africa }\end{array}$ & $\begin{array}{l}\text { No. of } \\
\text { these } \\
\text { types with } \\
\text { images } \\
\text { online }\end{array}$ & $\begin{array}{c}\% \\
\text { imaged }\end{array}$ & $\begin{array}{l}\text { Types of } \\
\text { names } \\
\text { for which } \\
\text { images } \\
\text { are not } \\
\text { available } \\
\text { online }^{\mathrm{a}}\end{array}$ \\
\hline K & 96 & 72 & 75 & 5 \\
\hline $\mathrm{BM}$ & 44 & 17 & 37 & 9 \\
\hline W & 39 & 2 & 5 & 7 \\
\hline S & 35 & 30 & 86 & - \\
\hline PRE & 27 & 19 & 70 & 4 \\
\hline M & 25 & 14 & 56 & 4 \\
\hline $\mathrm{G} / \mathrm{GDC}$ & 22 & 13 & 59 & 4 \\
\hline$Z^{b}$ & 20 & 5 & 25 & 8 \\
\hline $\mathrm{E}$ & 19 & 2 & 11 & 3 \\
\hline SAM & 19 & 18 & 95 & - \\
\hline BOL & 16 & 10 & 63 & 5 \\
\hline HBG & 16 & 11 & 69 & 1 \\
\hline $\mathrm{P}$ & 12 & 2 & 17 & 6 \\
\hline $\mathrm{UPS}^{\mathrm{b}}$ & 11 & 0 & 0 & 8 \\
\hline $\mathrm{OXF}^{\mathrm{b}}$ & 8 & 0 & 0 & - \\
\hline COI & 7 & 2 & 29 & 3 \\
\hline LD & 5 & 2 & 40 & - \\
\hline LISU & 5 & 0 & 0 & 4 \\
\hline MO & 5 & 5 & 100 & - \\
\hline NY & 5 & 4 & 80 & - \\
\hline CGE & 4 & 1 & 25 & - \\
\hline TCD & 4 & 2 & 50 & - \\
\hline FR & 3 & 1 & 33 & - \\
\hline B & 2 & 0 & 0 & 2 \\
\hline GRA & 2 & 2 & 100 & - \\
\hline KW & 2 & 2 & 100 & - \\
\hline LINN & 2 & 2 & 100 & - \\
\hline $\mathrm{NH}$ & 2 & 2 & 100 & 1 \\
\hline WAG & 2 & 2 & 100 & - \\
\hline BREM & 1 & 1 & 100 & - \\
\hline GOET & 1 & 1 & 100 & - \\
\hline $\mathrm{JE}$ & 1 & 1 & 100 & - \\
\hline PRU & 1 & 0 & 0 & 1 \\
\hline REG & 1 & 1 & 100 & - \\
\hline SBT & 1 & 1 & 100 & - \\
\hline SRGH & 1 & 1 & 100 & - \\
\hline TUB & 1 & 1 & 100 & - \\
\hline
\end{tabular}

a Recorded in the literature.

b Non-GPI partner. noted that he examined material from several herbaria, specific reference was not made to herbaria that hold the specimens he chose as types. The same approach had previously been followed by W.H. Harvey who was based at TCD when he produced the account of Polygala for Flora Capensis (Harvey $\&$ Sonder, 1860). Harvey referred to material under collector and number without mention of the herbarium where it was held. He did however cite herbaria holding duplicates as TCD, K ("Hooker"), HBG ("Sonder"). In addition to these herbaria, several other herbaria hold duplicates of these collections. The existence of numerous syntypes and isosyntypes results in problems in the typification of Harvey's names. The same applies to C.F. Ecklon \& C.L.P. Zeyher, whose names are based on collections that were dispersed as duplicates to several herbaria. Typification in these cases, particularly when the collections are unnumbered, is often extremely difficult, if not impossible.

Types of southern African Polygala online. - Of the 477 type specimens recorded in this study, 254 (53\%) are imaged online (Table 5), and 246 (97\%) of these are accessible through

Table 3. Number of names for southern African Polygala published during ca. 50 year intervals, from 1753 to the present.

\begin{tabular}{ll}
\hline Period & Number of names \\
\hline $1753-1800$ & 15 \\
$1801-1850$ & 61 \\
$1851-1900$ & 74 \\
$1901-1950$ & 26 \\
$1951-2000$ & 11 \\
$2001-2013$ & 1 \\
\hline
\end{tabular}

Table 4. Main authors of names of southern African Polygala.

\begin{tabular}{lccc}
\hline & $\begin{array}{c}\text { Names } \\
\text { published }\end{array}$ & $\begin{array}{c}\text { Important dates } \\
\text { or periods } \\
\text { of activity }\end{array}$ & $\begin{array}{c}\text { Main herbarium } \\
\text { where types and } \\
\text { collections held }\end{array}$ \\
\hline $\begin{array}{l}\text { Chodat, R.H. } \\
\text { (1865-1934) }\end{array}$ & 52 & $1893-1912$ & G \\
$\begin{array}{l}\text { De Candolle, A.P. } \\
(1778-1841)\end{array}$ & 20 & 1824 & GDC \\
$\begin{array}{l}\text { Harvey, W.H. } \\
(1811-1866)\end{array}$ & 18 & 1860 & TCD \\
$\begin{array}{l}\text { Presl, K.B. } \\
(1794-1852)\end{array}$ & 9 & 1845 & PR \\
$\begin{array}{l}\text { Ecklon, C.F. } \\
\text { (1795-1868) } \\
\text { \& Zeyher, C.L.P. } \\
(1799-1858)\end{array}$ & 8 & 1835 & $\begin{array}{c}\text { Dispersed (Ecklon) } \\
\text { SAM (Zeyher) }\end{array}$ \\
$\begin{array}{l}\text { Thunberg, C.P. } \\
(1743-1828)\end{array}$ & 8 & 1800 & UPS \\
$\begin{array}{l}\text { Levyns, M.R. } \\
(1890-1975)\end{array}$ & 7 & 1955 & BOL \\
$\begin{array}{l}\text { Linnaeus, C. } \\
\text { (1707-1778) }\end{array}$ & 6 & $1753-1782$ & LINN \\
\hline
\end{tabular}


JGP (i.e., $52 \%$ of the total). When holotypes only are considered the percentage of e-accessible type images is lower, as only 31 of the 72 extant specimens are imaged, i.e., $43 \%$. The absence of images results from a lack of type labels or other indications of their status on the specimens, or the specimens are not being kept in red folders, as is common practice in many herbaria. This can easily result in those specimens not having been imaged for the GPI. Lectotype specimens (including those that are being designated as lectotypes during the current revision of Polygala) are 67\% imaged. Thus, 31 images of holotypes and 47 images of lectotypes, amounting to $55 \%$ of the holo-/lectotypes recorded in this case-study, are accessible through JGP.

Excluding those images of specimens subject to lectotypification, an examination of the metadata associated with the images at JGP revealed that only $59(27 \%)$ have the correct type designation. The metadata of most of the remaining images (74\%) had no information on the sort of type (68 images), no information on whether the material has a recognised type status (33), or no updated indication of typification (22). Of particular concern are the 40 images (18\%) that have an incorrect type designation. These errors seem to be mostly due to misinterpretation of the literature. Some GPI partners captured metadata for images to be sent to JGP using unqualified digitizers and databasers; these data were generally not reviewed by specialists prior to submission to JGP. To avoid the accidental introduction of errors into metadata sets submitted to JGP, some other institutions opted to describe their material as "Filed as", without type status, whereas others chose to use "Type". As a result, information is essentially lacking for all such images, which in our case-study amount to $45 \%$ of the total for southern African Polygala accessible at JGP. In many cases, the correct information on the type status of a specimen is provided on the actual image (for example as a label) but not in the metadata.
Table 7. Names of southern African Polygala without type images online.

\begin{tabular}{ll}
\hline Names without type specimen images online & 57 \\
Accepted names & 22 \\
Names with syntypes & 10 \\
Holotypes extant or likely to exist & 30 \\
Lectotypes extant & 13 \\
Syntypes or isotypes extant & 9 \\
No type material extant & 5 \\
\hline
\end{tabular}

Considering these images together with those for which typification information has not been updated, there is a high percentage of images at JGP for which information is lacking $(55 \%)$. This is a consequence of JGP having to rely on institutions holding the specimens to inform them of changes in the (type) status of a specimen. Should JGP assume greater curatorial autonomy over the e-resource they hold, this situation would no doubt improve significantly. At present, all changes that have to be made to metadata must originate from the institution that holds the specimens. Even though many corrections can be easily made directly in the metadata, the system does not permit it.

Southern African Polygala names without types online. - For a total of 57 names of Polygala from the FSA region there are no type specimen images available online anywhere (Table 7). Twenty-two of these names represent $25 \%$ of the accepted taxa recorded for the region. Type material exists for the great majority of these names; only five appear to have no known type material (Table 7). Of the 17 herbaria (Table 2) that are known to hold type material for the 52 names that have no images online, 15 are GPI partners.

Table 5. Imaging of type specimens of southern African Polygala names.

\begin{tabular}{|c|c|c|c|c|c|c|c|}
\hline & Total & $\begin{array}{l}\text { Images } \\
\text { online }\end{array}$ & $\begin{array}{c}\text { Images } \\
\text { available } \\
\text { at JGP }\end{array}$ & $\begin{array}{c}\text { Images } \\
\text { available at } \\
\text { other sites }\end{array}$ & $\begin{array}{c}\text { Not } \\
\text { imaged }\end{array}$ & $\begin{array}{c}\text { Not imaged, } \\
\text { held by GPI } \\
\text { partners }\end{array}$ & $\begin{array}{l}\text { Not imaged, } \\
\text { held by non-GPI } \\
\text { partners }\end{array}$ \\
\hline Type specimens ${ }^{\mathrm{a}}$ & 477 & 254 & 246 & 8 & 223 & 188 & 35 \\
\hline Holotypes (extant) & 72 & 31 & 29 & 2 & 41 & 19 & 22 \\
\hline Lectotypes $^{\mathrm{b}}$ & 70 & 47 & 45 & 2 & 23 & 21 & 2 \\
\hline
\end{tabular}

${ }^{a}$ Including duplicates, e.g., iso-, isolecto-, syn-, isosyn-, but not paratypes.

${ }^{\mathrm{b}}$ Including those that will soon be designated as lectotypes.

Table 6. Information on types of southern African Polygala names available at JGP. Those specimens under consideration for lectotypification of some names are not included in the numbers.

\begin{tabular}{ccccc}
\hline $\begin{array}{c}\text { Images } \\
\text { analysed }\end{array}$ & $\begin{array}{c}\text { Type } \\
\text { designation } \\
\text { correct }\end{array}$ & $\begin{array}{c}\text { Type } \\
\text { designation } \\
\text { wrong }\end{array}$ & $\begin{array}{c}\text { No indication } \\
\text { of sort of type } \\
\text { ("Type" only) }\end{array}$ & $\begin{array}{c}\text { No information } \\
\text { ("Filed as ...") }\end{array}$ \\
\hline 222 & 59 & 40 & 68 & 33 \\
\hline
\end{tabular}




\section{CONCLUSION AND RECOMMENDATIONS FOR DEVELOPMENT OF THE FACILITY}

This study was conducted on a group of attractive plants with distinct horticultural potential and that make very good herbarium specimens. It is more than likely that the situation will differ depending on which plant group is analysed. For example, large and bulky specimens (pine cones, palm fruit and fronds) are awkward to image using standard scanning equipment, and institutions that do not have access to a good photographic laboratory or production chain will likely neglect or delay imaging such specimens. Therefore, although we are not suggesting that our results are representative of the situation overall, it may well be much worse in other, poorly studied and less attractive groups. In all cases, the best way to have data quality improved in institutional holdings, as well as in JGP, is to have in-house or outsourced taxonomic expertise available in JSTOR to enable the GPI to capture and disseminate published revision-based outputs, especially typifications, which can then also be fed back to institutions. This feedback can help improve data accuracy in the databases of herbaria where the types are housed.

To summarise, in our case-study it was found that JGP holds images of $52 \%$ of the types of names in Polygala from the southern African region. However, $74 \%$ of these images have incorrect metadata or no information at all on the type status of the specimens. In addition, $25 \%$ of the accepted taxa we recorded do not have type images online. This gap can be mostly filled by current GPI partners as they hold the majority of the types not imaged. It would appear that they are unaware that these types are in their collections.

Based on the results of this analysis we conclude the following:

- Forty-eight percent of the types of Polygala from southern Africa do not have images available online. A joint effort among institutions holding the material needs to be made to locate and image these types.

- Even though there is good representation of types of Polygala from southern Africa at JGP, the information associated with the images is deficient and needs reviewing and correcting in order to be maximally useful and to avoid misinterpretations. This can only be done by qualified taxonomists. JGP can either employ these taxonomists or outsource this function. Ideally, to maintain accurate and robust information, the dataset held by JGP will need the active involvement of dedicated specialists.

- Exclusive reliance on institutions to feed information on types to JGP may well result in a slow but steady and inevitable decline in the quality of the information held by the facility as many of these institutions face economic constraints, lack of human resources, and inadequate nomenclatural expertise.

- Even though the specimens imaged belong to the partner institutions, the information associated with them does not. In our view this information is in the public domain. At present, all corrections to the metadata must originate from the institutions that provided the images. Using such a cumbersome system makes it very unlikely that the JGP resource will ever achieve the information accuracy and reliability that is needed by all. It is our view that this information should be corrected within the JGP platform, in the same way that it can be corrected in any published revision without necessarily being corrected on the actual specimen with a label indicating the new type status. The institutions that provided the images can be informed of the corrections.

- Type images that are missing can mostly be sourced from current GPI partners but this activity is labour intensive, immensely expensive and time consuming as it often means that staff will have to conduct dedicated searches of the collections for specific specimens. With financial constraints prevalent in most herbaria, the required capacity is often inadequate or entirely absent. Funding needs to be sourced for this activity and JGP may want to consider including this expense in their not-for-profit funding model. A small number of-or even one-contracted taxonomists could significantly enhance the quality of the specimen metadata held by JGP.

- JGP could provide links to existing resources at nonpartner institutions that make scans of types available. This would enhance the status of JGP as a one-stop shop for online images of types of plant names.

The images of botanical specimens and artifacts, and data associated with them, which are held by JGP represent some of the most useful content for botanical - especially taxonomic - research work. Every effort should be made by GPI partners, in association with JGP, to maintain and enhance the immense utilitarian value of the resource.

\section{ACKNOWLEDGEMENTS}

The Andrew W. Mellon Foundation is thanked for financial support for the Global Plants Initiative, and its forerunners, the African Plants Initiative and the Latin American Plants Initiative. The continued support and guidance on the initiative by Mr. Bill Robertson of the Andrew W. Mellon Foundation is greatly appreciated, as is the support of Curators and project managers at participating herbaria. Mr. Robertson kindly read the manuscript. Dr. John McNeill, Royal Botanic Garden, Edinburgh, kindly read and commented on an earlier draft of the paper. Two anonymous referees and Dr. Gerry Moore are thanked for comments.

\section{口 LITERATURE CITED}

Figueiredo, E. \& Smith, G.F. 2010. The colonial legacy in African plant taxonomy. S. African J. Sci. 106(3/4): 5-7. http://dx.doi.org/10.4102/sajs.v106i3/4.161

Global Plants Initiative Steering Committee 2013. Terms of Reference. Unpub. report discussed at the GPI Steering Committee meeting held in January 2013 in Panama City, Panama.

Harvey, W.H. \& Sonder, O.W. 1860. Flora capensis, vol. 1. Dublin: Hodges, Smith \& Co.

Marhold, K., Stuessy, T., Agababian, M., Agosti, D., Alford, M.H., Crespo, A.M., Crisci, J.V., Dorr, L., Ferencová, Z., Frodin, D., Geltman, D.V., Kilian, N., Linder, H.P., Lohmann, L.G., Oberprieler, G., Penev, L., Smith, G.F., Thomas, W., Tulig, M., Turland, N. \& Zhang, X.-C. 2013. The future of botanical 
monography: Report from an international workshop, 12-16 March 2012, Smolenice, Slovak Republic. Taxon 62: 4-20.

Miéville, C. 2010. Kraken. London: Macmillan.

Paiva, J. 1998. Polygalarum africanarum et madagascariensium prodromus atque gerontogaei generis Heterosamara Kuntze, a genere Polygala L. segregati et a nobis denuo recepti, synopsis monographica. Fontqueria 50: 1-346.

Smith, G.F. 2004. The African Plants Initiative: A big step for continental taxonomy. Taxon 53: 1023-1025.

http://dx.doi.org/10.2307/4135568
Smith, G.F. \& Figueiredo, E. 2010. E-taxonomy: An affordable tool to fill the biodiversity knowledge gap. Biodivers. \& Conservation 19: 829-836. http://dx.doi.org/10.1007/s10531-009-9738-8

Smith, G.F., Roux, J.P., Raven, P. \& Figueiredo, E. 2011. African herbaria support transformation on the continent. Ann. Missouri Bot. Gard. 98: 272-276. http://dx.doi.org/10.3417/2010050

Walters, M., Smith, G.F. \& Crouch, N.R. 2010. The African Plants Initiative (API) in South Africa. Taxon 59: 1943-1946. 